\title{
BRINQUEDOS PEDAGÓGICOS - RECICLAGEM
}

\author{
Eleuza de Souza Borba Rezende ${ }^{1}$ \\ Jaqueline dos Santos Silvério ${ }^{2}$
}

RESUMO: Existe uma grande importância na educação infantil. Mas para que isso aconteça, muito tempo tem sido gasto nessa educação que não é necessária e a criança é tratada como outro ser da sociedade. Hoje, lhe é dado o devido valor, com direitos constitucionais, e da maneira que almejamos um mundo melhor nele, ensina-o a não cometer os erros do passado. Graças ao Brincar, podemos orientar sobre a importância da preservação do meio ambiente, conscientizando e nos divertindo.

Palavras-chave: Educação. Criança. Brincar.

ABSTRACT: There is great importance in early childhood education. But for this to happen, a lot of time has been spent on this education that is not necessary and the child is treated as another being in society. Today, it is given its due, with constitutional rights, and the way we aim for a better world in it, teaches it not to make the mistakes of the past. Thanks to Brincar, we can provide guidance on the importance of preserving the environment, raising awareness and having fun.

Keywords: Education. Child. Play.

\section{INTRODUÇÃO}

A relevância da Educação Infantil nos dias atuais é tamanha que é possível ver de forma significativa a evolução da visão social sobre a criança, as preocupações, assim como leis que amparam e dão direitos a elas. Hoje, há um estímulo precoce para aprendizagem, visando o futuro e o desenvolvimento das capacidades motoras, psicológicas, afetivas e, principalmente, o relacionamento social, considerando a educação escolar como ponte para a formação da criança. E quando acrescentamos o

\footnotetext{
I Graduada em Pedagogia pelo Centro Universitário de Jales, Especialista em Educação Infantil pela Faculdade Luso Capixaba.

${ }^{2}$ Graduada em Pedagogia pela Faculdade Afirmativo, Especialista em Educação Infantil pela Faculdade INVEST de Ciências e Tecnologias.
} 
ensino com conscientização, preservação, o aprendizado fica mais completo, como brincar com brinquedos reciclados, uma forma diverdita de orientar.

\section{DESENVOLVIMENTO 2.I Educação Infantil e o Brincar}

$\mathrm{Na}$ Idade Média a criança não era vista com olhos diferentes, como alguém que precisasse de um cuidado especial ou de uma educação específica, era tratada igual aos adultos, só lhe faltava ainda o treinamento para as atividades necessárias para sobrevivência. Dessa forma, eram consideradas como uma subclasse que amadureceria e tornaria-se um ser "racional".

$\mathrm{Na}$ Idade Mordena, há atenção e cuidados específicos para criança, que foram percebidos ser diferente dos adultos. No seculo XIX, registros nos mostram Friedrich Froebel, que viveu de 1782 a 1852 e foi um fundador dos primeiros modelos de instituição para educação infantil, utilizava jogos e brincadeiras no aprendizado.

Froebel defendia ainda que, quanto mais ativa é a mente da criança, mais ela é receptiva a novos conhecimentos. Assim, considerando os sentidos da criança, o contato que ela cria com o mundo, respeitando os estágios de capacidade de aprendizado e suas características específicas, é que deve ser o ponto de partida para o ensino (FERRARI 2008).

Mas, somente em 1988 quando houve a Constiuição da República, começou-se a tratar a educação com importância, dando o direito a criança de tê-la. Incumbiu-se o governo de garantir esse direito. Em 1990, o ECA (Estatuto da Criança e do Adolecente) reafirmou esses direitos constitucionais em relação à Educação Infantil. Quatro anos depois, o MEC (Ministério da Educação e Cultura) publicou um documento para expansão de vagas e melhorias de atendimento, ressaltando a necessidade da qualificação do profissional e uma formação para atender a Educação Infantil.

A Educação Infantil tornou se responsabilidade de Municipio, na rede pública de ensino, oferecido também pela iniciativa privada, sob a supervisão do sistema municipal de ensino. Saliento que não é obrigatoriedade o Município oferecer a Educação Infantil. Cabe ao município através de um estudo oferecê-lo. 
A relevância da Educação Infantil cresce com passar dos tempos, o que tem acarretado crianças melhores em todos os aspectos. Umas das características, dentre muitas, é o brincar acompanhando o crescimento dessa educação diferenciada da pré-escola. Assim, também temos estudiosos que ressaltam que a importância do brincar na formação educacional é de significado tão grande para criança como trabalhar para um adulto, isso a faz feliz e a torna mais propensa a ter uma personalidade bondosa e amável.

\subsection{Brincar}

Piaget diz que a criança exploradora, construindo seu conhecimento, dando enfasê na inter-relação do ambiente com o individuo, compreende a utilidade $e$ funcionamento das estruturas do mundo.

Vygotsky aponta o brincar na primeira infância um meio para o desenvolvimento psicológico e sócio-cultural da criança, sendo fundamental pelo fato de poder criar situações diversas, de forma que imaginaria aquilo que passaria despercebido pela criança na brincadeira se torna regra.

Wallon defende o brincar e o brinquedo juntos como uma forma de estruturação do Eu da criança. Esse é um meio que possibilita a construção da personalidade. Quando se tem um espaço organizado para isso e a disponabilidade desse material, isso fundamentaria a fluidez das emoções e pensamentos, dando-lhe mais conhecimento para se desenvolver uma pessoa completa.

Brincar nos mostra a importância de se movimentar, pois através disso nos relacionamos com os outros, meio ambiente, aprendemos mais sobre nós, limites, capacidades e solucionar problemas. Ainda encontramos pessoas que não desenvolveram as habilidades básicas, prejudicando assim seu desenvolvimento posterior. Por isso, a importância da atividade física, principalmente nas séries iniciais, como em todas as séries. Essa sociabilidade nos remete a uma caracteristica que é pecebida: a participação das atividades apenas por prazer, sem espera de recompensa ou castigo, assim, brincando, a criança busca um sentido para vida. 


\subsection{Brincar com brinquedos - sucatas}

Todo brinquedo confeccionado com material reciclável tende a dispertar nas crianças novos interesses, desenvolve grandiosamente a criatividade, mostrando as possibilidades de transformar objetos e também a destreza manual na confecção dos brinquedos. Pode ser em grupo, ensinando a interação social e a dividir o espaço. Essa atividade é recebida com muita euforia nas aulas, há muitas possibilidades para criação, as cores, formas, objetos, fazendo a criatividade se desenvolver mais ainda.

Agora imaginemos todo esse aprendizado, junto com conscientização de meio ambiente, já que nos dias de hoje se fala tanto em qualidade de vida, sustentabilidade.

Existem inúmeras possibilidades de práticas pedagógicas para se realizar isso dentro de sala de aula. Imaginemos projetos e trabalhos escolares que podemos fazer nas datas comemorativas, como semana do Meio Ambiente, Dia da Árvore ou dia da água. Enfim, acredito que daríamos, além de ensino, também a conscientização.

Brincar com brinquedo reciclado não é apenas lazer, estimulação da criatividade ou outros aspectos relevantes na criança, ou ainda um bom gerenciamento do lixo. Quero abordar esse assunto como algo mais complexo, pois ao ter essa prática exercemos uma ação direta no meio ambiente e, consequentemente, na economia, no comportamento humano e na cultura de nosso país, que ainda não tem a prática habitual da reciclagem. Estamos orientando e conscientizando para a Educação Ambiental e os resultados serão grandes, pois haverá mudança nos valores e comportamento das crianças, como alunos e pessoas em sociedade

\subsection{Reciclar}

Hoje, vivemos um crescimento populacional muito grande. Com isso, crescem as indústrias e a quantidade de resíduos orgânicos e inorgânicos. Dados de pesquisas nos mostram que, desde 1980 , a produção desses resíduos tem aumentado consideravelmente. Para ter uma pequena noção, a produção de lixo por dia de uma pessoa é aproximadamente de $5 \mathrm{~kg}$. Imagine isso em nível mundial. Só no Brasil, produzimos 240.000 toneladas por dia, incluindo todo tipo de lixo doméstico, tecnológicos, radioativos, hospitalar, agrícola, industrial. Por isso, a reciclagem, que 
significa transformar resíduos já utilizados em novos produtos, tem sido uma das soluções para uma vida sustentável.

\subsection{Importância da reciclagem}

Entendamos que, quando reciclamos, além de preservar o meio ambiente e gerar riquezas materiais com os produtos reciclados (vidro, papel, plástico, alumínio...), contribuímos para a diminuição da poluição de solo, ar e água. Essa relevância se abrange a outros segmentos do nosso dia a dia, que nos atingem de forma direta e indireta, como a economia, saúde, entre outros.

\subsection{Os benefícios da reciclagem}

A sociedade tem sido umas das mais beneficiadas com o trabalho da reciclagem. Hoje, muitas empresas estão adotando o processo de reciclagem para reduzir de forma significativa os custos da produção, visando menos poluição para o meio ambiente principalmente para as metrópoles. Estão sendo gerados muitos empregos através deste trabalho. Cooperativas estão sendo criadas e dando oportunidade e renda para muitas famílias carentes.

Hoje, esta orientação está nas escolas. Muitas crianças, adolescentes e jovens, são orientados a separar seu lixo dentro de casa, sabendo que existe a reciclagem para todo tipo de lixo, principalmente os eletrônicos. Há empresas que adotaram certas medidas que podem ser tomadas como exemplo. Quando uma pessoa vai comprar uma pilha ou qualquer tipo de bateria, se pede para que leve as que ele não usa mais e sejam encaminhadas para os centros de reciclagem.

Se todos soubermos como utilizamos os recursos que temos, seja orgânico ou inorgânico, com consciência em breve teremos um mundo mais limpo, sustentável e mais desenvolvido. É nesse caminho que poderemos alcançar o tão sonhado desenvolvimento sustentável do planeta.

\subsection{Escola, família e os cuidados com o meio ambiente}

A educação ambiental nasceu para dar consciência ecológica ao ser humano. Essa educação na família e escola estão totalmente ligadas como um ciclo 
completo, precisam andar em conjunto para funcionar. São as fontes de aprendizado das primeiras idades, pois devem iniciar esse ensinamento. A criança precisa ser orientada a preservar a natureza no seio familiar e na escola, isso nos mostra o quão importante é que a família tenha uma base de conhecimento prévio para passar. E na escola principalmente, pois é onde nascem os formadores de idéias.

Segundo Munhoz (2004), uma das formas de levar educação ambiental à comunidade é pela ação direta do professor na sala de aula e em atividades extracurriculares. Através de atividades como leitura, trabalhos escolares, pesquisas e debates, os alunos poderão entender os problemas que afetam a comunidade onde vivem; levados a refletir e criticar as ações de desrespeito à ecologia, a essa riqueza que é patrimônio do planeta, e, de todos os que nele se encontram. E ainda diz: Os professores são a peça fundamental no processo de conscientização da sociedade dos problemas ambientais, pois, buscarão desenvolver em seus alunos hábitos e atitudes sadias de conservação ambiental e respeito à natureza, transformando-os em cidadãos conscientes e comprometidos com o futuro do país.

Esse laço tende a se fortalecer mais para que obtenha sucesso na orientação ambiental pedagógica, lembrando que estamos visando um futuro não distante. É preciso agirmos com consciência.

\section{CONCLUSÃO}

Como professores, devemos estar atentos a todos os problemas que nos preocupam em nosso dia a dia, respeitando as crianças de hoje e tratando-as como o futuro de amanhã, porque hoje elas nos tornaram criadoras de idéias, comportamentos e atitudes.

Saber que uma criança precisa de passar pelas suas etapas, que procura um sentido para a sua vida e que nós seremos seus guias, mostra-me mais uma vez a importância que têm para a sociedade, para os professores e para os futuros professores.

Quando aliamos essa educação à sustentabilidade, surge outro desafio que devemos superar. Pelo menos para nós, ajudarmos a mudar uma cultura que é desprovida de hábitos saudáveis tanto para nós como para a natureza, inspira-me a 
procurar ser o melhor, não só o melhor. Mas também para aqueles que irão aprender conosco, de certa forma, já sabíamos o que fazer, agora só precisamos agir.

\section{REFERENCIAS}

ANTUNES, C. Educação Infantil Prioridade imprescindível. Petrópolis: Vozes 2004. Cria Revista da Educação Infantil (Revista). Ano I. Numero 2 Março/Abril/Maio.

FERRARI, M. Friedrich Freobel: o formador das crianças pequenas. Revista Nova Escola. Edição Especial: compilação dos volumes i e 2 dos Grande Pensadores. jul 2008.

BALDWIN, A. L. Teorias do Desenvolvimento da Criança. São Paulo: Pioneira, 1973.

REIGOTA, Marcos. O que é Educação Ambiental? São Paulo: Ed. Brasiliense, 1994 